\title{
A CONTINUIDADE DO CONTRATO DE TRABALHO COMO PRESSUPOSTO DE VALORIZAÇÃO DO TRABALHO HUMANO
}

\author{
Lourival José de Oliveira ${ }^{1}$ \\ Larissa Vasconcelos Naves ${ }^{2}$
}

\begin{abstract}
RESUMO
Com os avanços e alterações tecnológicas sofridas pelas empresas, em razão do fenômeno da globalização e da crescente competitividade de produtos e serviços no mercado, tornam-se constantes as dispensas imotivadas de massas de trabalhadores na busca de reduzir custos e assegurar uma maior lucratividade. Ocorre que preceito constitucional existe garantindo a proteção da relação de emprego face às despedidas arbitrárias ou sem justa causa, estando, contudo, ressalvada a necessidade de legislação complementar a regulamentálo, cabendo indenização compensatória ao empregado até que esta sobrevenha. Intentou-se com o presente estudo demonstrar que a norma constitucional sobre direito social fundamental do homem, que é o direito ao trabalho, ser de aplicação imediata, o que significa independer de regulamentação. Ressalvou-se, ainda, o caráter imperioso da apresentação pelo empregador de justificativa socialmente relevante para admissão das dispensas, tanto individuais como coletivas. Ademais, quis-se evidenciar ser a garantia ao trabalho requisito para a valorização do trabalho humano e instrumento de preservação da dignidade do trabalhador, não podendo ser substituída pela forma indenizatória.
\end{abstract}

Palavras-chave: Proteção da relação de emprego. Valorização do trabalho humano. Dignidade do trabalhador; manutenção do emprego; proteção do trabalho humano.

\begin{abstract}
With the advances and technological changes experienced by companies as a result of globalization and the increasing competitiveness of products and services to market, become the constant unmotivated mass layoffs of workers seeking to reduce costs and achieve greater profitability. It turns out that there is constitutional provision guaranteeing protection of the employment relationship against the arbitrary dismissal or without cause, subject, however, subject to the need for additional legislation to regulate it, being compensatory damages to an employee until that ensues. Brought up to the present study demonstrate that the constitutional provision on fundamental social right of man, which is the right to work, be applied immediately, which means independent of regulation. It should be understood, though, the imperious character of the presentation by the employer to justify socially relevant to admission of layoffs, both individual and collective. Furthermore, we wanted to highlight the

\footnotetext{
1 Atualmente é professor associado da Universidade Estadual de Londrina onde também é professor do Curso de Mestrado em Direito Negocial, professor da Faculdade Paranaense e Professor do Curso de Mestrado em Direito da Universidade de Marília.

${ }^{2}$ Graduação em andamento em Direito . Universidade Estadual de Londrina, UEL, Brasil.
} 
security requirement to work for the enhancement of human labor and means to preserve the dignity of the worker can not be replaced by way of damages.

Keywords: Protection of the employment relationship. Enhancement of human labor. Dignity of workers; maintaining employment, protection of human labor.

\section{INTRODUÇÃO}

Instala-se cotidianamente nas sociedades contemporâneas um cenário de eliminação de postos de trabalho e de descarte da mão-de-obra humana face às constantes transformações e avanços tecnológicos sofridos pelas empresas que visam garantir precipuamente sua maior lucratividade.

Como reflexo do desemprego crescente, as desigualdades econômicas e sociais aumentam, intensificam-se as exclusões e as vítimas da pobreza, elevam-se os níveis de violência nas comunidades.

Diante desse quadro é que se questiona a possibilidade do empregador rescindir unilateralmente o contrato de trabalho no momento que lhe convém, sem a necessidade de fundamentar seu ato. Como conviver com as dispensas imotivadas, praticadas livremente, em uma realidade de desemprego e miséria?

Estabeleceu o legislador constituinte no art. $7^{\circ}$, inciso I, da Constituição Federal estar a relação de emprego protegida contra as despedidas arbitrárias ou sem justa causa. Contudo, previu regulamentação do dispositivo por legislação complementar, assegurando indenização compensatória ao empregado até que aquela sobrevenha.

Nada obstante, seria tal indenização instrumento eficaz para inibir as denúncias vazias dos contratos de trabalho? Ademais, poder-se-ia compreender que a proteção ao emprego é preceito constitucional de aplicação imediata mesmo estando prevista legislação futura a regulamentá-la?

O Direito do Trabalho surgiu para resguardar o trabalhador, em sua qualidade de ser humano, ante as liberdades contratuais que sempre representaram a vontade do empregador, a parte economicamente mais forte. Sua finalidade é, pois, proporcionar melhores condições de trabalho e preservar a dignidade do trabalhador. 
Nesta perspectiva, trazer à tona questões envolvendo a continuidade do contrato de trabalho mostra-se imperioso diante da realidade brasileira marcada pelo o desemprego e por inúmeras mazelas decorrentes deste.

\section{DA PROTEÇÃO CONSTITUCIONAL CONTRA A DESPEDIDA ARBITRÁRIA OU SEM JUSTA CAUSA}

Um dos maiores problemas sociais da atualidade é, indubitavelmente, o desemprego. Em uma sociedade marcadamente capitalista, em que prevalece a busca incessante pela lucratividade, o desemprego aniquila o ser humano, destrói sua auto-estima e causa uma série de problemas a toda a sociedade ${ }^{3}$.

Fator que contribui para essa anomalia social é a forma de regulamentação das relações de trabalho. A facilidade jurídica atribuída aos empregadores para dispensarem seus empregados provoca grande rotatividade de mão-de-obra, que impulsiona o desemprego e favorece, ainda mais, a insegurança nas relações trabalhistas, além de fragilizar a situação do trabalhador e precarizar as condições de trabalho.

Ante esse crescente esfacelamento das relações empregatícias, é que a Constituição Federal institui em seu art. $7^{\circ}$, inciso I, a proteção ao emprego contra a despedida arbitrária ou sem justa causa.

Com o objetivo de preservar os direitos e garantias fundamentais do trabalhador, de modo a propiciar o seu desenvolvimento e progresso humano, a Constituição torna-se o instrumento para sua valorização quando preceitua a proteção da relação empregatícia frente ao seu rompimento desmotivado.

Em contrapartida, o texto constitucional, no mesmo art. $7^{\circ}$, inciso I, parte final, condiciona essa proteção à lei complementar, prevendo, ainda, o pagamento de indenização compensatória ao empregado despedido de forma arbitrária ou sem justa causa.

Tal condicionante, no entanto, mostra-se na contramão do que preceitua a própria Constituição, que estabelece em seu art. $1^{\circ}$, inciso III e IV, serem fundamentos da República Federativa do Brasil a dignidade da pessoa humana e os valores sociais do trabalho, e institui em seu art. 170, caput, a valorização do trabalho humano e uma existência digna a todos.

\footnotetext{
${ }^{3}$ MAIOR, Jorge Luiz Souto. Proteção contra a dispensa arbitrária e aplicação da Convenção 158 da OIT. Disponível em: http://bdjur.stj.jus.br/jspui/bitstream/2011/18352/2/Prote\%C3\%A7\%C3\%A3o_Contra_a_Dispensa_Arbitr\%C3 \%A1ria.pdf. Acesso em: 15 jan. 2009.
} 
Portanto, fixar um parâmetro de segurança nas relações de trabalho, que preserve o homem no contexto produtivo e faça prevalecer a justiça social, é papel e objetivo maior de toda a ordem jurídica brasileira.

\subsection{Conceito De Despedida Arbitrária ou Sem Justa CAusa}

Para conceituar despedida arbitrária ou sem justa causa necessário entender, precipuamente, como se dá a terminação do contrato empregatício.

Os contratos, inclusive o de trabalho, extinguem-se em virtude de um fato que lhes põe fim. Podem deixar de existir de forma normal, ou seja, por sua simples execução ${ }^{4}$, e de forma anormal, ou seja, pelo surgimento de causas supervenientes à formação do contrato e nele, portanto, não previstas como motivo normal para o desfazimento do vinculo ${ }^{5}$.

Denomina-se dissolução a extinção contratual pela via que não seja normal. São modalidades de dissolução a resolução, rescisão e resilição ${ }^{6}$.

A resilição corresponderia a todas as modalidades de ruptura do contrato de trabalho por exercício lícito da vontade das partes ${ }^{7}$. Classifica-se em dissolução bilateral ou unilateral. A primeira ocorre quando as próprias partes, de comum acordo, deliberam desfazer o contrato, é o denominado distrato. A segunda dá-se quando uma das partes decide findar o contrato, o qual se pressupõe ser por prazo indeterminado.

A dissolução unilateral do contrato de trabalho se dá tanto por ato do obreiro, o que se denomina pedido de demissão, como por ato do empregador, que é a chamada dispensa ou despedida do empregado.

Segundo Amauri Mascaro Nascimento ${ }^{8}$ "dispensa é a ruptura do contrato de trabalho por ato unilateral e imediato do empregador, independente da vontade do empregado".

A este direito de terminação do contrato de trabalho por uma das partes contratantes, nomeia a doutrina de direito potestativo, uma vez que a declaração de vontade que põe fim à relação jurídico independe da aceitação de seu destinatário, ou seja, tem caráter receptício, assim como constitui novo estado jurídico para as partes, caráter constitutivo.

\footnotetext{
${ }^{4}$ SUSSEKIND, Arnaldo; MARANHÃO, Délio; VIANNA, Segadas; TEIXEIRA, Lima. Instituições de direito do trabalho. 20. ed. São Paulo: LTr, p. 548, 2000. v. 1.

${ }^{5}$ MARANHÃO, Délio; CARVALHO, Luiz Inácio B. Direito do trabalho. 17. ed. Rio de Janeiro: Fundação Getúlio Vargas, 1993. p. 233.

${ }^{6}$ MARANHÃO; CARVALHO, loc. cit.

${ }^{7}$ DELGADO, Maurício Godinho. Curso de direito do trabalho. 7. ed. São Paulo: LTr, 2008, p. 1124.

${ }^{8}$ NASCIMENTO, Amauri Mascaro. Curso de direito do trabalho. 23. ed. São Paulo: Saraiva, 2008, p. 782.
} 
Trata-se, portanto, a despedida arbitrária ou sem justa causa de uma espécie de resilição unilateral do contrato em que o empregador põe fim à relação empregatícia por sua exclusiva vontade.

É possível constatar, pois, que esse poder de dispensa prescinde de justificação, exercendo o empregador esse direito no momento que lhe convém. Contudo a este direito de dispensa há limitações impostas por lei, como por exemplo, as estabilidades provisórias, bem como pela própria Constituição ao instituir, no art. $7^{\circ}$, inciso $\mathrm{I}$, a proteção da relação de emprego contra despedida arbitrária ou sem justa causa.

Comumente a expressão "despedida arbitrária ou sem justa causa" suscita dúvidas e entendimentos conflitantes, uma vez que, conforme Arion Sayão Romita ${ }^{9}$ a despedida arbitrária abrange inegavelmente as hipóteses em que não há justa causa. No entanto, o mesmo doutrinador esclarece que deflui do texto constitucional duas figuras distintas, com contornos específicos e diferenciados, posto que a Constituição não contém palavras inúteis, possuindo significação própria as expressões despedida arbitrária e despedida sem justa causa $^{10}$.

A despedida sem justa causa, segundo Roland Hasson ${ }^{11}$, guarda correlação de antônimo com a despedida com justa causa, a qual possui definição legal expressa. Prevista no art. 482 e incisos da Consolidação das Leis do Trabalho (CLT), a despedida com justa causa tem como característica da dispensa a existência de motivos disciplinares, ou seja, há um comportamento negativo do empregado que merece repressão. Desta forma, a despedida sem justa causa apresenta-se como sinônimo de dispensa sem motivo disciplinar (justa causa).

Quanto à definição de despedida arbitrária, esta já era apontada pela legislação laboral pátria antes mesmo de ser mencionada no texto constitucional. Conceitua a CLT em seu art. 165 como sendo despedida arbitrária aquela que não se funda em motivo disciplinar, técnico, econômico ou financeiro.

Enunciação próxima ao conceito de despedida arbitrária dado pelo art. 165 da CLT pode ser extraída do texto do art. $4^{\circ}$ da Convenção $n^{\circ} 158$ da Organização Internacional do Trabalho, in verbis:

\footnotetext{
${ }^{9}$ ROMITA, 1994 apud CARVALHO. Weliton Sousa. Despedida arbitrária no texto constitucional de 1988. Curitiba: Juruá, 1998, p. 76.

${ }^{10}$ ROMITA, 1991 apud ROBORTELLA, Luiz Carlos Amorim. O moderno direito do trabalho. São Paulo: LTr, 1994, p. 193.

${ }^{11}$ HASSON, Roland. Desemprego e desproteção. Curitiba: Juruá, 2006. p. 41.
} 
Art. $4^{\circ}$. Não se dará término à relação de trabalho de um trabalhador a menos que exista para isso uma causa justificada relacionada com sua capacidade ou seu comportamento ou baseada nas necessidades de funcionamento da empresa, estabelecimento ou serviço.

Plausível obter de tal enunciado algumas semelhanças com o texto laboral, como a necessidade da existência de motivo disciplinar (causa relacionada á capacidade ou ao comportamento do empregado), motivos técnico, econômico ou financeiro (causa ligada ao funcionamento da empresa) para que a dispensa não seja realizada de forma arbitrária.

Imprescindível, então, compreender a significação de tais pressupostos.

O motivo técnico diz respeito à atividade produtiva da empresa. Estaria, pois, ligado aos avanços tecnológicos de equipamentos capazes de dinamizar a produção e que, não raro, implicam na diminuição da necessidade de mão-de-obra ${ }^{12}$.

Salienta-se, no entanto, que a dispensa é última opção para o empregador, o qual deve primeiramente verificar a possibilidade de reciclar, readaptar ou reintegrar o empregado em outra função na empresa, minorando, assim, os efeitos do uso de novas tecnologias ${ }^{13}$.

Quanto ao motivo financeiro, este diz respeito à saúde financeira da empresa e traz como razões justificantes para uma despedida questões afetas a balanços, equilíbrio entre receita e despesa, à liquidez dos ativos, ao controle de estoques, enfim, toda uma gama de aspectos gerenciais que ao final terminam por decidir a imperiosidade da dispensa de mão-deobra.

As razões de ordem econômica, embora afetem as razões de ordem financeira, caracterizam-se por sua amplitude, uma vez que decorrem da inserção da atividade empresarial no contexto mais amplo da economia mundial. Com isso, o motivo econômico está atado ao custo de produção da atividade empresarial, apresentando como fatores relevantes para sua análise os índices inflacionários, os indicadores de recessão, as políticas públicas de fomento, a livre concorrência e toda uma situação econômica conjuntural que provoca o enxugamento na classe dos trabalhadores.

\subsection{Da InsuficiÊnCia Da Multa Do FGTS PARA IMPEDIR A DESPEDIDA ARbitrÁRIA}

Até o advento da Lei 5.107/1966, existia no ordenamento jurídico brasileiro, previsto pela CLT, um sistema de proteção ao tempo de serviço prestado pelo empregado e ao contrato

\footnotetext{
12 Ibidem, p. 61.

${ }^{13}$ MARTINS. Sérgio Pinto. A continuidade do contrato de trabalho. São Paulo: Atlas, 2000, p. 271.
} 
de trabalho que combinavam dois institutos, o da indenização crescente por tempo de serviço e da estabilidade no emprego. No entanto, com a concepção da referida lei instituiu-se alternativamente a esse sistema o regime do Fundo de Garantia do Tempo de Serviço (FGTS), o qual tinha por objetivo unicamente garantir indenização ao empregado nos casos de dispensa.

Unificado pela Constituição Federal de 1988 e estendido a todos os trabalhadores urbanos e rurais, o regime do FGTS, atualmente disciplinado pela Lei 8.036 de 11.05.90, consiste no recolhimento pecuniário mensal, em conta bancária vinculada, realizado pelo empregador em favor do empregado, sendo os depósitos efetuados créditos legais decorrentes da execução do contrato de trabalho ${ }^{14}$.

Inexistindo a segurança da manutenção do emprego advinda com a estabilidade e imposto o regime do FGTS apenas como espécie de poupança a ser sacada pelo empregado nas hipóteses previstas em lei ${ }^{15}$, anteviu a Constituição Federal a necessidade de instrumento inibidor da denúncia vazia do contrato de trabalho pelo empregador. Para tanto, estabeleceu o pagamento de indenização nos casos das dispensas arbitrárias ou sem justa causa.

Nos termos do art. $7^{\circ}$, inciso I, da CF, fica "a relação de emprego protegida contra despedida arbitrária ou sem justa causa, nos termos de lei complementar que preverá indenização compensatória, dentre outros direitos”. Em não tendo sido promulgada lei complementar regulamentadora do mencionado dispositivo, determina o art. 10, inciso I, do Ato das Disposições Constitucionais Transitórias (ADCT), o pagamento pelo empregador de indenização de $40 \%$ sobre os depósitos do FGTS.

Pode-se concluir que a Constituição Federal, ao prever indenização compensatória ao empregado nos casos de dispensa imotivada, intencionava dificultar o despedimento do mesmo, tornando, para isso, mais onerosa a ação do empregador. Reforçando tal posicionamento, o art. 10, inciso I, do ADCT, vem aumentar em quatro vezes o valor da indenização prevista, antes fixada pela Lei 5.107/66 no montante de 10\% sobre os depósitos do FGTS.

Desta forma, ao se atribuir obrigação ao empregador de pagar indenização compensatória abalizada nos depósitos do FGTS, somada às demais verbas rescisórias, o aviso prévio e outros direitos assegurados em normas e convenções coletivas, acreditou o

\footnotetext{
${ }^{14}$ MARANHÃO; CARVALHO, op. cit., p. 296.

${ }^{15}$ MARTINS, op. cit., p. 232.
} 
legislador constituinte ter tornado suficientemente dispendiosa a terminação imotivada da relação de emprego, chegando mesmo a impedir as despedidas arbitrárias ou sem justa causa.

Contudo, nas palavras de Sérgio Pinto Martins ${ }^{16}$

O sistema contido no inciso I, do artigo 10 do ADCT, efetivamente, não protege o trabalhador contra a dispensa arbitrária. O empregador acaba preferindo pagar a indenização de $40 \%$ do FGTS do que manter o contrato de trabalho do empregado. O levantamento do FGTS, com a indenização de $40 \%$ não é a mesma coisa que a garantia do emprego.

Não visa o FGTS efetivamente combater o desemprego, mas proporcionar ao empregado minorar os efeitos do desemprego, de forma temporária, pois tem um valor que pode servir-lhe para a sua subsistência, enquanto não consegue outra colocação para trabalhar.

Não há que se negar, então, que a instituição do regime do FGTS resultou na fragilização do nível de emprego e na redução do poder de barganha dos trabalhadores, provocando inúmeras deformações no modelo de relações de trabalho no país, possibilitando ainda mais as dispensas injustificadas e arbitrárias ${ }^{17}$.

Indubitável que para o empregador o valor da indenização do FGTS e das verbas rescisórias não servirá como fator inibidor das despedidas imotivadas, uma vez que mostra ser quantia irrisória diante da possibilidade de contratação de mão-de-obra mais barata.

Há de se salientar, ainda, que o crescente desemprego sobrecarrega a previdência social, gerando gastos para o Estado, os quais irão repercutir, de forma inevitável, no bolso do contribuinte, e causa a degeneração da saúde física e mental da sociedade, levando à violência, fome e miséria ${ }^{18}$.

Além disso, a instabilidade criada pela dispensa do empregado abala sua segurança, leva à sua marginalização e prejudica a edificação de uma sociedade justa ${ }^{19}$.

\subsection{DA ApliCAÇÃo IMEDiata Do ART. 7º, InCiso I, Da CONSTITUIÇÃo FEDERAL}

Ter a relação de emprego protegida é direito fundamental de todo trabalhador urbano e rural brasileiro, conforme determinação do art. $7^{\circ}$, inciso I, da CF.

\footnotetext{
${ }^{16}$ Ibidem, p. 237.

${ }^{17}$ CORTEZ, Rita de Cássia S.; XAVIER, José Luis Campos. Sobre a Convenção 158 da OIT, ratificada pelo Brasil, sobre o término do trabalho por iniciativa do empregador. Revista LTr. São Paulo, v 60, n. 4, p.505, abr. 1996.

${ }^{18}$ ARRUDA, Kátia Magalhães. Direito constitucional do trabalho: sua eficácia e o impacto do modelo neoliberal. São Paulo: LTr, 1998, p. 87.

${ }^{19}$ Ibidem, p. 82.
} 
Contudo, discussão há no tocante à eficácia da mencionada norma jurídica, a qual, para inúmeros doutrinadores, permanece inaplicável em razão da ausência de lei reguladora por ela referida.

Não obstante a negação à executoriedade de direito fundamental do trabalhador, corrente doutrinária já há que se opõe a tal entendimento, afirmando a supremacia da Constituição, a qual prescindiria de norma inferior para lhe dar efetividade, como bem assevera Kátia Magalhães Arruda ${ }^{20}$

[...] a Constituição tem força normativa, é superior à norma comum e, por consequiência, não necessita de uma norma inferior para lhe dar validade ou garantir sua eficácia. As normas hierarquicamente inferiores devem ser interpretadas nos estritos limites de suas atribuições de complementação, ordenação ou regulação, e não como instrumento sem o qual a Constituição fica inerte.

Relevante ressaltar que sempre que se estuda a Constituição e sua força normativa, várias problematizações e análises surgem quanto à eficácia de seus preceitos. O desafio de se outorgar à ordem constitucional e, de modo especial, aos direitos fundamentais nela consagrados, sua plena operatividade e eficácia, como condição para sua efetividade, permanece atual e corrente ${ }^{21}$.

Tida, em diversas sociedades e por algum tempo, apenas como força diretiva, privada de qualquer imperatividade, representando tão somente uma indicação ao legislador futuro, a Constituição inúmeras vezes viu-se destituída, em muitos de seus preceitos, de efetivo teor normativo, ficando eles limitados a meras proposições abstratas, mais próximas de comandos morais $^{22}$.

No entanto, salienta Konrad Hesse ${ }^{23}$ que a Constituição contém em si força própria, não configurando apenas "expressão de um ser mas também de um dever ser”, imprimindo ordem e conformação à realidade política e social. É, pois, força motivadora e ordenadora da vida do Estado, convertendo-se em um fator real de poder, influindo e recebendo influência dos fatos sociais ${ }^{24}$.

\footnotetext{
${ }^{20}$ Ibidem, p. 42.

${ }^{21}$ SARLET, Ingo Wolfgang. A eficácia dos direitos fundamentais. 9. ed. Porto Alegre: Livraria do Advogado, 2008. p. 249.

${ }^{22}$ BARROSO, Luís Roberto. O direito constitucional e a efetividade de suas normas: limites e possibilidades da Constituição Brasileira. 7. ed. Rio de Janeiro: Renovar, 2003. p. 79.

${ }^{23}$ HESSE, Konrad. A força normativa da constituição. Porto Alegre: Sergio Antonio Frabris Editor, 1991. p. 15.

${ }^{24}$ ARRUDA, op. cit., p. 40.
} 
Desta feita, se as normas de uma Constituição são privadas de sua eficácia, seu texto não passará de letra morta, uma vez que o seu conteúdo não será incorporado à conduta humana e deixará, por conseguinte, de garantir direitos e liberdades que a qualificam como lei maior $^{25}$.

Em razão disto é que afirma Luís Roberto Barroso ${ }^{26}$

As normas constitucionais, como espécie do gênero normas jurídicas, conservam os atributos essenciais destas, dentre os quais a imperatividade. De regra, como qualquer outra norma, elas contêm um mandamento, uma prescrição, uma ordem, com força jurídica e não apenas moral. Logo, a sua inobservância há de deflagrar um mecanismo próprio de coação, de cumprimento forçado, apto a garantir-lhe a imperatividade, inclusive pelo estabelecimento das consequiências da insubmissão ao seu comando. As disposições constitucionais são não apenas normas jurídicas, como têm caráter hierarquicamente superior, não obstante a paradoxal equivocidade que longamente campeou nesta matéria, considerando-as prescrições desprovidas de sanção, mero ideário não jurídico.

Eficácia jurídica da norma quer significar, para José Afonso da Silva ${ }^{27}$, a capacidade desta atingir os objetivos nela traduzidos, consistindo, pois na qualidade de produzir efeitos jurídicos. Portanto, a eficácia jurídica nada mais é do que a aplicabilidade, exigibilidade ou executoriedade da norma, posto serem aspectos do mesmo fenômeno, encarados por prismas diferentes: a eficácia como potencialidade e aplicabilidade como realizabilidade.

Nesta senda, afirma ainda o mencionado autor possuir eficácia todas as normas constitucionais, sendo aplicáveis nos limites objetivos de seu teor normativo. Por fim, baseado na lição de Ruy Barbosa, assevera não existir norma constitucional de valor meramente moral de conselhos, avisos e lições, tendo sim força imperativa ${ }^{28}$.

A doutrina clássica tem apresentado distintas classificações entre as normas constitucionais no que toca à sua efetividade e aplicabilidade, explicando, assim, a ausência de produção de seus efeitos ainda que em vigor no ordenamento jurídico.

José Afonso da Silva ${ }^{29}$, em obra célebre sobre a eficácia e aplicabilidade das normas constitucionais, sustenta divisão tricotômica destas, sendo as normas divididas em: I - normas constitucionais de eficácia plena e aplicabilidade direta, imediata e integral, as quais desde a entrada em vigor da constituição produzem seus efeitos essenciais; II - normas de eficácia

\footnotetext{
${ }^{25}$ Ibidem, p. 45.

${ }^{26}$ BARROSO, op. cit., p. 78.

${ }^{27}$ SILVA, José Afonso da. Aplicabilidade das normas constitucionais. 7. ed. São Paulo: Malheiros, 2007, p. 66.

${ }^{28}$ Ibidem, p. 80.

${ }^{29}$ Ibidem, p. 82-84.
} 
contida e aplicabilidade direta, imediata, mas não integral, que produzem seus efeitos, mas prevêem meios que permitem manter sua eficácia contida em certos limites e circunstâncias; III - normas de eficácia limitada e aplicabilidade indireta, mediata e reduzida, vez que não produzem com sua entrada em vigor os seus efeitos imediatos, dividindo-se em: a) declaratórias de princípios institutivos ou organizativos e b) declaratórias de princípios programáticos.

Em razão dessa categoria de normas é que diversos doutrinadores entendem ser de eficácia limitada o art. $7^{\circ}$, I, da CF, uma vez que o mesmo faz menção a legislação complementar futura, ficando suspenso os efeitos que poderiam ser produzidos por ele.

Ocorre que, em razão da inércia do legislador nacional, já se passaram mais de vinte anos de vigência da Constituição Federal de 1988 sem que qualquer atividade legislativa se desse no sentido de implementação do dispositivo supramencionado, permanecendo o trabalhador brasileiro sujeito a ver o término de sua relação de emprego ao bel prazer do empregador.

Propondo uma nova sistematização sobre a efetividade das normas constitucionais, Luís Roberto Barroso ${ }^{30}$ apresenta três grupos distintos de norma, que são: I - as normas constitucionais de organização, que têm por objeto organizar o exercício do poder político; II - normas constitucionais definidoras de direito, cujo objeto é fixar os direitos fundamentais dos indivíduos, as quais para o autor estão ligadas à idéia de direito subjetivo (entendido como o poder de ação, assente no direito objetivo e destinado à satisfação de certo interesse); III - normas constitucionais programáticas, que têm por objeto traçar os fins públicos a serem alcançados pelo Estado.

Por meio dessa classificação, afirma o autor que as normas constitucionais definidoras de direitos, na qual se enquadra o direito fundamental de proteção à relação de emprego, resultam para os seus beneficiários - titulares do direito - situações jurídicas imediatamente desfrutáveis, a serem materializadas em prestações positivas ou negativas. Tais prestações são exigíveis do Estado e se não efetuadas conferem ao titular do direito a possibilidade de postular-lhes o cumprimento, inclusive por meio de ação judicial ${ }^{31}$.

Ademais, está positivada pelo art. $5^{\circ}, \S 1^{\circ}$, da Constituição Federal a aplicação imediata das normas definidoras dos direitos e garantias fundamentais.

\footnotetext{
${ }^{30}$ BARROSO, op. cit., p. 94.

${ }^{31}$ Ibidem, p. 105.
} 
Nada obstante, vários são os dispositivos de direitos fundamentais da Carta Magna que orientam o intérprete à lei complementar para dar aplicabilidade a estes, como se pode verifica do art. $7^{\circ}$, inciso I. Kátia Magalhães Arruda ${ }^{32}$ traz alguns apontamentos no que toca à essa questão, assim compreendendo

que o direito poderá ser regulamentado, esclarecendo sobre o seu alcance, mas nunca proibindo seu exercício ou restringindo-o ao ponto de torná-lo inútil, sob pena de haver ultraje à vontade do legislador constituinte e, por conseqüência, de ser passível de descumprimento e resistência em face da sua inconstitucionalidade. A lei complementar em face da Constituição tem a capacidade de regular e não de estabelecer direitos. Os direitos já foram estabelecidos, portanto, são passiveis de exercício e de ação, conforme disciplinado na Constituição Federal, em seu art. 5', XXXV: 'A lei não excluirá da apreciação do Poder Judiciário lesão ou ameaça a direito'.

Resta claro que os direitos sociais trabalhistas, fundamentais que são, possuem plena eficácia, ainda que o legislador constituinte tenha feito menção à lei futura, posto serem tais direitos instrumentos de potencialização, libertação, desenvolvimento e dignificação do homem ${ }^{33}$.

Assim, uma relação de emprego protegida de dispensas arbitrárias ou sem justa é garantia do trabalhador nacional, o qual a qualquer momento pode reivindicá-la, uma vez que está consolidada em norma supra que é a Constituição Federal.

\section{DA PROTEÇÃO À CONTINUIDADE DO CONTRATO DE TRABALHO}

A aceleração da revolução tecnológica e as inúmeras transformações sofridas pela sociedade nos últimos tempos têm acarretado uma maior competitividade de mercado, levando à extinção de postos de trabalho e à substituição do homem pela máquina.

Tornam-se frequientes as dispensas imotivadas de massas de trabalhadores em função única e exclusivamente da busca pela lucratividade. Contudo, se a curto prazo o descarte do trabalho enquanto finalidade econômica e até mesmo enquanto fator de produção em setores genéricos da economia representa ganho na redução de custos e diminuição de preços, a médio e longo prazo gera o rompimento do precário equilíbrio do sistema, acirrando a competição entre grupos, nações e etnias ${ }^{34}$.

\footnotetext{
${ }^{32}$ ARRUDA, op. cit., p. 61.

${ }^{33}$ Ibidem, p. 62.

${ }^{34}$ FEIX apud PETTER, Josué Lafayete. Princípios constitucionais da ordem econômica: significado e alcance do art. 170 da Constituição Federal. 2. ed. São Paulo: Revista dos Tribunais, 2008, p. 169.
} 
Sem trabalho, os homens perdem o referencial enquanto homens modernos e não sabem o que fazer das mãos e mentes desocupadas, e muito menos o que fazer para o sustento próprio e das suas famílias ${ }^{35}$, o que gera cada vez mais violência e desgraças sociais.

Imprescindível a proteção do trabalhador face á possibilidade das denúncias vazias dos contratos de trabalho e uma limitação às demissões em massa de milhares de trabalhadores, despejados no mercado de trabalho a cada ano, vez que resguardar o direito ao trabalho é proporcionar a existência digna da pessoa humana e potencializar a justiça social.

\subsection{Da Necessidade Da Fundamentação Por Parte Do Empregador Nas Rescisões CONTRATUAIS}

Ao Direito do Trabalho interessa a permanência do vínculo empregatício, primando sempre pela integração do trabalhador na estrutura e dinâmica empresariais, em vista que a extinção contratual transcende o simples interesse individual das partes, causando os mais amplos impactos na comunidade em que está inserido o trabalhador. Nessa direção é que o mencionado ramo jurídico tende a reprimir as modalidades de ruptura do contrato de trabalho que não se fundem em causa jurídica relevante ${ }^{36}$.

Salientando os impactos causados com o fim da relação de emprego, Mauricio Godinho Delgado ${ }^{37}$ assevera que

[...] o desemprego não interessa à sociedade como um todo. Causa o desemprego impacto negativo de múltiplas dimensões (econômicas, sociais, psicológicas etc.) sobre a pessoa do trabalhador atingido; porém, contamina, na mesma profundidade, o âmbito comunitário que cerca o desempregado, em especial sua família. Tratando-se de desemprego maciço, o impacto atinge toda a sociedade, com a desestruturação do sistema de convivência interindividual e comunitária e o agravamento das demandas sobre o sistema estatal de seguridade e previdência social. A par disso, o desemprego acentua a diferenciação social, alargando a chaga da exclusão de pessoas e grupos sociais, que tanto conspira contra a Democracia. Mais ainda, esse fenômeno acaba por colocar todo o sistema econômico em perigosa antítese ao papel social que a ordem jurídica determina seja exercida pela propriedade.

Deste modo, não podem as rescisões contratuais ser disciplinadas segundo um princípio de plena liberdade de uma das partes com quanto que o uso indiscriminado do poder

\footnotetext{
${ }^{35}$ FEIX, loc. cit.

${ }^{36}$ DELGADO, op. cit., p. 1099-1100.

${ }^{37}$ Ibidem, p. 1100.
} 
de despedir pode assumir proporções que afetam o próprio sentido de justiça social, alicerce das relações individuais e coletivas de trabalho ${ }^{38}$.

A idéia trazida pela doutrina clássica de que existiria uma igualdade formal entre empregado e empregador no momento da feitura do contrato de emprego e do desfazimento deste, estando as partes numa posição de paridade, devendo por isso ter o mesmo tratamento na rescisão contratual, é uma inverdade, e sempre foi, uma vez que é nítida a condição de inferioridade daquele que tem tão apenas a força de trabalho para sobreviver enquanto o outro nada tem a perder.

O trabalhador, como parte hipossuficiente na relação, suporta desvantagens de ordem econômica, política, financeira e social comparativamente ao empregador. E é para equilibrar essa relação e deixar as partes em igualdade de condições que se torna imprescindível o papel da norma jurídica, desempenhada pelo Estado, concretizando, pois, a verdadeira igualdade substancial, fundamento para o alcance da justiça social ${ }^{39}$.

Em razão disto é que se compreende ser permitido o rompimento do contrato de trabalho somente na presença de justificativas legal e socialmente relevantes.

Denominado por Mauricio Godinho Delgado ${ }^{40}$ de critério motivado para a validação das rupturas contratuais trabalhistas, seria esse mecanismo uma forma de incorporação pelo ordenamento laboral brasileiro de uma sistemática de causas jurídicas relevantes como fatores propiciadores da extinção do contrato empregatício, incentivando, desta forma, a permanência dos contratos de trabalho, além de ser importante elemento de afirmação do princípio da continuidade da relação de emprego que rege aqueles.

E acrescenta que mesmo esse motivo não se consubstanciando em infração cometida pelo trabalhador (o que ensejaria resolução contratual por justa causa operária), deve ser ele razoável, sério e socialmente aceitável, fundando-se, assim, a dispensa em comprovados fatores econômico-financeiros, tecnológicos ou resultantes de objetiva mutação do mercado capitalista, os quais afetam, de maneira relevante, o empreendimento empresarial ${ }^{41}$.

Desta feita, para que não reste caracterizada a despedida arbitrária ou sem justa causa demonstrou-se em capítulo anterior que é imperiosa a prática de conduta reprovável pelo

\footnotetext{
${ }^{38}$ NASCIMENTO, op. cit., p. 782.

${ }^{39}$ PERPÉTUO, Daniel Lini. Direito do trabalhador à proteção contra a despedida imotivada - auto-aplicabilidade do inciso I, do art. $7^{\circ}$, da Constituição Federal de 1988. Âmbito Jurídico, Rio Grande, n. 22, ago. 2005. Disponível em: < http://www.ambito- juridico.com.br/site/index.php?n_link=revista_artigos_leitura\&artigo_id=475>. Acesso em: 25 abr. 2009.

${ }^{40}$ DELGADO, op. cit., p. 1109.

${ }^{41}$ Ibidem, p. 1153.
} 
empregado (justa causa) ou a presença de motivos técnicos, econômicos ou financeiros ligados diretamente ao regular funcionamento da empresa, justificando, pois, a cessação do contrato de trabalho.

O abandono daquele ideal de total liberdade do empregador para a dispensa do empregado tem por intento proporcionar uma relação de emprego mais duradoura e, por conseguinte, uma maior segurança ao trabalhador.

Importa destacar, ainda, que a proteção do trabalhador contra a dispensa injustificada é entendimento dominante na ordem jurídica de diversas nações, sendo a manutenção do trabalho objetivo precípuo destas, haja vista ser o trabalho a base de toda sociedade e componente essencial para o seu bom desenvolvimento econômico e social.

Nesta senda, trabalhou bem o legislador constituinte nacional ao restringir o poder resilitório do empregador, exigindo deste fundamentação jurídica e socialmente relevante quando da denúncia da relação de emprego, buscando o equilíbrio entre os interesses do empregador e os direitos dos trabalhadores e conciliar o desenvolvimento econômico com a justiça social.

\subsection{Da Garantia Ao Emprego Enquanto Requisito Para a ValorizaÇão Do Trabalho HUMANO}

A história do homem demonstra o liame existente entre o processo de evolução e desenvolvimento da sociedade humana e o trabalho ${ }^{42}$.

Compreendendo diversos sentidos, o trabalho adquire significado conforme o momento histórico vivenciado pela humanidade. Originariamente tido como tortura ou pena a ser cumprida por alguns integrantes da sociedade, o trabalho passa a ser concebido como a essência do homem, estando mesmo relacionado ao seu espírito ${ }^{43}$.

Fator de transformação da natureza e de produção de riquezas, o trabalho é instrumento de humanização ${ }^{44}$, e forma pela qual a pessoa humana se vê exteriorizar e se coloca diante dos outros ${ }^{45}$.

\footnotetext{
${ }^{42}$ PROSCURCION, Pedro. Compêndio de direito do trabalho: introdução às relações de trabalho em transição à nova era tecnológica. São Paulo: LTr, 2007. p. 27.

${ }^{43}$ ROMITA, Arion Sayão. Direito do trabalho: noções fundamentais. São Paulo: LTr, 1975. p. 11.

${ }^{44}$ GROSSO, Cristiano Pinheiro. Limites da flexibilização no direito do trabalho à luz do desenvolvimento econômico e social. Disponível em:

<http://www.unimar.br/pos/trabalhos/arquivos/8b357c913bbfa6970d06b7356171db57.pdf>. Acesso em : 6 abr. 2009.

${ }^{45}$ PETTER, op. cit., p. 167.
} 
Não raro, é o principal instrumento de satisfação da mais pura e simples necessidade de sobrevivência, no entanto, é o trabalho, sobretudo, modo de expressão direta da pessoa humana; é, pois, elemento social estruturante de sua personalidade; e, principalmente, é meio de dignificação e valorização daquela.

Portanto, é dever do Estado e demais agentes sociais assegurar o valor social do trabalho humano, para que este não venha a ser desvirtuado em função de interesses daqueles que guardam melhor posicionamento na pirâmide social. Trata-se, assim, de compreender o trabalho não como mercadoria, ultrapassando o seu significado o aspecto material de força de trabalho e produção, e sim como fundamento da vida humana.

Desta feita, se modernamente as sociedades se inserem num mundo globalizante marcado por ideologias liberais em cuja lógica o trabalho humano é apenas um fator de produção, a ser matematicamente equacionado na diagramação dos custos e dos lucros tãosomente, estas não podem prescindir do trabalhador e de valorizar o seu trabalho ${ }^{46}$, posto que a redução das pessoas empregadas faz reduzir, na mesma proporção, o potencial de consumo, desestabilizando social e economicamente todo o sistema ${ }^{47}$.

Garantir o acesso ao trabalho a todo indivíduo é sim evitar um colapso no desenvolvimento econômico de um país e, por conseguinte, no seu desenvolvimento nacional.

Desse modo, a garantia ao emprego é requisito essencial para valorizar o trabalho humano. Para o doutrinador Lafayete Josué Petter ${ }^{48}$ valorizar o trabalho humano significa proporcionar a existência de mais postos de trabalho, a maior oferta de trabalho e o melhor trabalho ao cidadão, acomodando-se nesta última expressão todas as alterações físicas que repercutam positivamente na própria pessoa do trabalhador.

Exsurge da Constituição Federal brasileira a obrigação do Estado em afiançar o direito ao trabalho. Interpretação sistêmica do texto constitucional permite deduzir que o direito à garantia ao emprego ${ }^{49}$ está informado por princípios fundamentais que colocam o trabalho no contexto dos valores sociais $\left(\right.$ art. $6^{\circ}$ ) e o insere como primado da ordem social (art. 193). Ademais, a ordem econômica nacional funda-se na valorização do trabalho humano (art. 170, caput), tendo o Estado Democrático Brasileiro como fundamento o valor social do trabalho (art. $1^{\circ}$, IV).

\footnotetext{
${ }^{46}$ Ibidem, p. 169.

${ }^{47}$ FEIX apud PETTER, loc. cit.

${ }^{48}$ PETTER, loc. cit.

${ }^{49}$ LIMA NETO, Arnor. A proteção contra a despedida arbitrária ou sem justa causa do trabalhador brasileiro no contexto dos direitos fundamentais e sua efetividade. In: HASSON, Roland. Direito dos trabalhadores e direitos fundamentais. Curitiba: Juruá, 2003. p. 49.
} 
Logo, impedir as dispensas injustificadas é elevar a garantia ao emprego e, por conseguinte, valorizar o trabalho humano e propiciar a dignificação da pessoa humana.

De fato, a dignidade trabalhador engloba o respeito e proteção de conservar sua relação de emprego, mas também de ter acesso a essa relação. O direito ao trabalho surge em razão de a sociedade ser fundada no trabalho. E negar trabalho significa negar vida digna ao homem $^{50}$.

Nesta ordem de idéias, a instituição de um Estado Democrático destinado a assegurar o exercício de direitos sociais, o bem-estar, o desenvolvimento, a igualdade e a justiça como valores supremos de uma sociedade, impõe percorrer o caminho da dignificação do trabalhador, sem dúvida propiciada pela segurança da continuidade do vínculo empregatício ${ }^{51}$.

Valorizar o trabalho então é valorizar a pessoa humana e, conseqüentemente, repudiar sua degradação. Transformar o trabalho em um direito do homem é, enfim, proporcionar a potencialização das qualidades que o singularizam - humanidade- mais bem percebidas no quadrante solidarista e fraternal da justiça social ${ }^{52}$.

\subsection{Do IMPEDIMENTo PARA As DeSPEDIDAs EM MASSA}

O processo de mundialização do capital, responsável por introduzir novas tecnologias na indústria de diversas sociedades contemporâneas e reestruturar toda a sua atividade produtiva ${ }^{53}$, cada vez mais elimina postos de trabalho, leva a uma precarização da relação de emprego e cria a necessidade de uma maior qualificação técnica do trabalhador.

$\mathrm{O}$ argumento de que a concorrência e as modernas tecnologias exigem dos empresários um desempenho diferenciado, tendente à redução de custos e à busca de uma maior produtividade, ampliando, desse modo, a concorrência de seus produtos no mercado atual $^{54}$, torna-se justificativa para o descarte de milhares de trabalhadores.

Ademais, afirmam os defensores dos ideais neoliberais que o lucro obtido com menores custos, advindos da diminuição da mão-de-obra empregada, é reinvestido no

\footnotetext{
${ }^{50}$ PROSCURCION, op. cit., p. 61.

${ }^{51}$ LIMA NETO, op. cit., p. 51.

${ }^{52}$ PETTER, op. cit., p. 174.

${ }^{53}$ SILVA, Paulo Henrique Tavares da. Valorização do trabalho como principio constitucional da ordem econômica brasileira: interpretação crítica e possibilidades de efetivação. Curitiba: Juruá, 2003, p. 130.

${ }^{54}$ SALOMÃO, Claudia Regina. A dispensa coletiva no ordenamento jurídico brasileiro e a influência da Convenção n. 158 da OIT. Revista LTr, São Paulo, v. 72, n. 4, p. 444, abr. 2008.
} 
desenvolvimento de tecnologias e, por conseguinte, na criação de novos postos de trabalho, com a reabsorção das massas desempregadas ${ }^{55}$.

Todavia, nas palavras de Luiz Henrique S. Barbugiani ${ }^{56}$

O raciocínio sofismático de tal corrente desatenta-se da instabilidade inerente ao mundo globalizado, visto que a mutabilidade das tendências de consumo e da própria linha de produção altera-se drasticamente, conforme as modificações muitas vezes impingidas pela criação de um novo produto ou técnica de manufatura, gerando focos de desemprego a cada evolução da tecnologia mundial.

Nesse sentido, a dispensa de grande número de empregados que tinha a finalidade primeira de aumentar a lucratividade da empresa, a qual retornaria o proveito à sociedade por meio da oferta de empregos, termina por configurar mecanismo nefasto e vicioso, vez que leva a mais desempregos diante das constantes mudanças econômicas globais.

Com efeito, em todas as suas formas e principalmente na forma coletiva, a dispensa gera reflexos sociais e econômicos, afetando, não apenas o empregado atingido por ela, mas toda a sociedade de maneira irremediável, ganhando, sim, contornos de problema social, posto que agrava as desigualdades, a violência, a informalidade.

Portanto, controlar as despedidas coletivas por grandes detentores de capital faz-se imperioso quando ausente motivação socialmente relevante ou alegação fundada em dificuldade econômico-financeira da empresa, provável de acarretar danos reais à sua constituição, logo à classe de trabalhadores.

O ordenamento jurídico brasileiro, como se pode constatar, não possui dispositivos regulamentadores da dispensa coletiva, sendo esta, conforme Mauricio Godinho Delgado ${ }^{57}$, “descurada pelo Direito do Trabalho do país”. Não obstante, é prática corrente, existindo de fato e afetando inúmeros cidadãos nacionais.

A doutrina, em sua maioria, entende ser a dispensa coletiva aquela que atinge um grupo significativo de trabalhadores vinculados à respectiva empresa ${ }^{58}$, com fulcro em razão de ordem objetiva desta e comum a todos os que serão despedidos.

Conquanto inexistente legislação específica a tratar da despedida coletiva, esta se dá nos mesmos moldes da dispensa individual quando não há conduta ou comportamento

\footnotetext{
${ }^{55}$ BARBUGIANI, Luiz Henrique S. Globalização, economia e desemprego. Revista LTr, São Paulo, v. 73, n.1, p. 62, jan. de 2009 .

56 Ibidem, loc. cit.

${ }_{58}^{57}$ DELGADO, loc. cit., p. 1157.

${ }^{58}$ Ibidem, p. 1156.
} 
reprovável do empregado que resulte na resolução por justa causa do contrato de trabalho. Significa, pois, que, para serem válidas as rupturas contratuais de inúmeros trabalhadores, imprescindível a presença dos motivos técnicos, econômicos ou financeiros ligados diretamente ao funcionamento regular da empresa, como se compreende ser exigível na resilição unilateral do contrato de trabalho individual pelo empregador.

Neste vértice, indubitável que o art. $7^{\circ}$, inciso I, da Constituição Federal, que está a resguardar a relação de emprego face às despedidas imotivadas, abrangerá tanto as formas individuais como coletivas de dispensa, limitando a plena liberdade do empregador de romper com o vínculo empregatício injustificadamente.

Afora as situações excepcionais apontadas pela CLT, as rupturas contratuais em grande número, voltadas apenas a obtenção de uma maior lucratividade, serão, sem dúvida, uma frontal agressão aos princípios e regras constitucionais de valorização do trabalho humano, do bem-estar, da segurança e justiça sociais ${ }^{59}$.

Segundo Amauri Mascaro Nascimento ${ }^{60}$, o moderno direito do trabalho dirigi-se para uma compreensão da necessidade do controle da dispensa do trabalhador, mediante procedimentos que envolvem consultas às representações trabalhistas, autorizações administrativas e atuação jurisdicional, como se observa na legislação de diversos países europeus.

Assim versa a Convenção n.158 da OIT, estabelecendo ao empregador, quando do término da relação de trabalho por motivos econômicos, tecnológicos, estruturais ou análogos, a efetivação de uma consulta aos representantes dos trabalhadores e uma notificação à autoridade competente.

No Brasil, mesmo ausente no ordenamento jurídico pátrio previsão legal a regulamentar as dispensas coletivas, o entendimento doutrinário e jurisprudencial no tocante à prática dessa modalidade de dispensa é a imprescindibilidade de prévia negociação coletiva entre representantes dos empregados e empregadores.

Regida por princípios e regras do Direito Coletivo do Trabalho, na medida em que diz respeito a interesses de natureza coletiva e difusa, a dispensa de grande número de trabalhadores somente estaria autorizada quando precedida de negociação coletiva, com a presença obrigatória do sindicato dos obreiros, sendo facultativa a representação dos

\footnotetext{
${ }^{59}$ Ibidem, p. 1157.

${ }^{60}$ NASCIMENTO, op. cit., p. 802.
} 
empregadores por sindicato, vez que aqueles podem negociar diretamente com sindicato profissional, como ocorre nos acordos coletivos ${ }^{61}$.

Instrumento utilizado com o fim primeiro de se ajustar os interesses particulares das partes e encontrar uma solução capaz de compor suas posições, superando, assim, suas divergências, a negociação coletiva é procedimento imperativo no sistema brasileiro, do qual podem resultar as convenções e acordos coletivos ${ }^{62}$.

Nesse sentido é que se impõe a utilização de tal mecanismo previamente às dispensas de massas de trabalhadores, na tentativa de encontrar formas alternativas e menos danosas que as rupturas contratuais, bem como assegurar os direitos fundamentais dos empregados quando estas se fazem cogentes.

Controlar as dispensas abusivas e as contratações periódicas, que elevam a rotatividade da mão-de-obra, é procurar assegurar um equilíbrio entre o capital e o trabalho e, com isso, manter o poder aquisitivo do trabalhador, parte da massa de consumidores, estimulando investimentos e incrementos econômicos, tão almejados e essenciais para o desenvolvimento social.

\section{CONCLUSÃO}

Indubitável, pois, que impedir e dificultar as dispensas coletivas e individuais e resguardar a continuidade do contrato de trabalho é primar pela dignidade da pessoa humana, os valores sociais do trabalho, o bem-estar do cidadão e por uma sociedade livre, justa e solidária, pois é por meio do trabalho que o homem se desenvolve. O texto constitucional foi objetivo no sentido de não ser admitida a despedida arbitrária ou sem justa causa, o que concretiza o princípio da continuidade do trabalho, não podendo medidas paliativas ser aplicadas enquanto não se legisla eficazmente no plano ordinário a respeito do tema.

$\mathrm{Na}$ verdade, embora o texto constitucional aponte para a necessidade de regulamentação em sede de lei complementar, o artigo $7^{\circ}$, inciso I da Constituição Federal tem aplicação plena, imediata, independentemente de qualquer regulação. A regulamentação somente será bem vinda, de forma secundária, caso venha para estabelecer um procedimento uniforme de justificação das terminações contratuais e não querer substituir a continuidade da relação de trabalho por indenização.

\footnotetext{
${ }^{61}$ MARTINS, Sérgio Pinto. Direito do trabalho. 24. ed. São Paulo: Atlas, 2008, p. 775.

${ }^{62}$ Ibidem, p. 773.
} 
A forma indenizatória de compensar rescisões contratuais arbitrárias ou sem justa causa não se coaduna com o contido no mesmo dispositivo, o que significa que o próprio artigo 10, inciso I da ADCT, que estabelece a multa dos $40 \%$ sobre os valores do FGTS como forma de impedir a demissão desmotivada, também resta marcado pela inconstitucionalidade.

\section{REFERÊNCIAS BIBLIOGRÁFICAS}

ARRUDA, Kátia Magalhães. Direito constitucional do trabalho: sua eficácia e o impacto do modelo neoliberal. São Paulo: LTr, 1998.

BARBUGIANI, Luiz Henrique S. Globalização, economia e desemprego. Revista LTr, São Paulo, v. 73, n.1, p. 60-64, jan. 2009.

BARROSO, Luiz Roberto. O direito constitucional e a efetividade de suas normas: limites e possibilidades da constituição brasileira. 7. ed. Rio de Janeiro: Renovar, 2003.

CARVALHO, Weliton Sousa. Despedida arbitrária no texto constitucional de 1988. Curitiba: Juruá, 1998.

CONVENÇÃO n. 158 da Organização Internacional do Trabalho. Disponível em: http://www.ilo.org/ilolex/spanish/convdisp1.htm. Acesso em: 15 mai. 2009.

CORTEZ, Rita de Cássia S.; XAVIER, José Luis Campos. Sobre a Convenção 158 da OIT, ratificada pelo Brasil, sobre o término da relação do trabalho por iniciativa do empregador. Revista LTr. São Paulo, v 60, n. 4, p. 505-515, abr. 1996.

DELGADO, Maurício Godinho. Curso de direito do trabalho. 7. ed. São Paulo: LTr, 2008.

GROSSO, Cristiano Pinheiro. Limites da flexibilização no direito do trabalho à luz do desenvolvimento econômico e social. Disponível em: <http://www.unimar.br/pos/trabalhos/arquivos/8b357c913bbfa6970d06b7356171db57.pdf>. Acesso em : 6 abr. 2009.

HASSON, Roland. Desemprego e desproteção. Curitiba: Juruá, 2006.

HESSE, Konrad. A força normativa da constituição. Porto Alegre: Sérgio Antonio Fabris Editor, 1991.

LIMA NETO, Arnor. A proteção contra a despedida arbitrária ou sem justa causa do trabalhador brasileiro no contexto dos direitos fundamentais e sua efetividade. In: HASSON, Roland. Direito dos trabalhadores e direitos fundamentais. Curitiba: Juruá, 2003.

MAIOR, Jorge Luiz Souto. Proteção contra a dispensa arbitrária e aplicação da Convenção 158 da OIT. Disponível em:

http://bdjur.stj.jus.br/jspui/bitstream/2011/18352/2/Prote\%C3\%A7\%C3\%A3o_Contra_a_Dis pensa_Arbitr\%C3\%A1ria.pdf. Acesso em: 15 jan. 2009. 
MARANHÃO, Délio; CARVALHO, Luiz Inácio B. Direito do trabalho. 17. ed. Rio de Janeiro: Editora Fundação Getúlio Vargas, 1993.

MARTINS, Sérgio Pinto. Direito do trabalho. 24. ed. São Paulo: Atlas, 2008. A continuidade do contrato de trabalho. São Paulo: Atlas, 2000.

NASCIMENTO, Amauri Mascaro. Curso de direito do trabalho. 23. ed. São Paulo: Saraiva, 2008.

PERPÉTUO, Daniel Lini. Direito do trabalhador à proteção contra a despedida imotivada auto-aplicabilidade do inciso I, do art. $7^{\circ}$, da Constituição Federal de 1988. Âmbito Jurídico, Rio Grande, n.22, 31 ago. 2005. Disponível em:<http://www.ambitojuridico.com.br/site/index.php?n_link=revista_artigos_leitura\&artigo_id=475>. Acesso em: 25 abr. 2009.

PETTER, Josué Lafayete. Princípios constitucionais de ordem econômico: significado e alcance do art. 170 da Constituição Federal. 2. ed. São Paulo: Revista dos Tribunais, 2008.

PROSCURCIN, Pedro. Compêndio de direito do trabalho: introdução às relações de trabalho em transição à nova era tecnológica. São Paulo: LTr, 2007.

ROBORTELLA, Luiz Carlos Amorim. O moderno direito do trabalho. São Paulo: LTr, 1994.

ROMITA, Arion Sayão. Direito do trabalho: noções fundamentais. São Paulo: LTr, 1975.

SALOMÃO, Claudia Regina. A dispensa coletiva no ordenamento jurídico brasileiro e a influência da Convenção n. 158 da OIT. Revista LTr. São Paulo, v.72, n. 4, abr. de 2008, p. 444-450.

SARLET, Ingo Wolfgang. A eficácia dos direitos fundamentais. 9. ed. Porto Alegre: Livraria do Advogado, 2008.

SILVA, José Afonso. Aplicabilidade das normas constitucionais. 7. ed. São Paulo: Malheiros, 2007.

SILVA, Paulo Henrique Tavares da. Valorização do trabalho como principio constitucional da ordem econômica brasileira: interpretação crítica e possibilidades de efetivação. Curitiba: Juruá, 2003.

SÜSSEKIND, Arnaldo; MARANHÃO, Délio; VIANNA, Segadas; TEIXEIRA, Lima. Instituições de direito do trabalho. 20. ed. São Paulo: LTr, 2000. v.1. 